\title{
Effect of solution treatment on microstructure and hardness of rheo-forming AZ91-Y alloy
}

\author{
Zhi-wei Wang', 2 *Hong Yan ${ }^{1,2}$, and Wen-xian Huang ${ }^{3}$ \\ 1. Department of Materials Processing Engineering, School of Mechanical Electrical Engineering, Nanchang University, Nanchang 330031, China; \\ 2. Key Laboratory of Light Alloy Preparation \& Processing, Nanchang 330031, China; \\ 3. Department of Civil Engineering, School of Architectural Engineering, Jinggangshan University, Ji'an 343009, China
}

\begin{abstract}
The microstructure and hardness of rheo-forming AZ91-Y alloy before and after solution treatment (ST) have been investigated by means of optical microscope (OM), scanning electron microscope (SEM) equipped with energy dispersive spectroscopy (EDS), X-ray diffraction (XRD) and Vickers. The experimental results showed that the $\beta-\mathrm{Mg}_{17} \mathrm{Al}_{12}$ phase of alloy was nearly dissolved after ST for $5 \mathrm{~min}$. With the increasing of ST duration to $28 \mathrm{~h}$, both the primary and secondarily solidified $\alpha-M g$ grains faded away. At the same time, the alloy exhibited a much smoother surface due to the diffusion of solute atoms (AI). During ST, the thermal stable phase of $\mathrm{Al}_{2} \mathrm{Y}$ produced by ultrasonic vibration retained its size and morphology. As the ST duration was increased, the alloy hardness decreased sharply at first, and then gradually reached a minimum level. The alloy's appropriate ST duration at $410^{\circ} \mathrm{C}$ was approximately $28 \mathrm{~h}$.
\end{abstract}

Key words: AZ91 alloy; rheo-forming; rare earth; solution treatment; hardness
CLC numbers: TG146.22
Document code: A
Article ID: 1672-6421(2016)06-383-06

$\mathrm{M}$ g-Al series alloys have been recognized as ideal materials for lightweight applications in the automotive industry with great development potential because of their low density, high specific strength and stiffness, and excellent cast-ability ${ }^{[1-2]}$. But their applications are still limited due to the intermetallic phase $\mathrm{Mg}_{17} \mathrm{Al}_{12}$ of easy brittleness and unstable structure at elevated temperatures ${ }^{[3-4]}$.

Some efforts have focused on adding some elements like $\mathrm{Ca}, \mathrm{Si}$, rare earth $(\mathrm{RE})$ into the alloy matrix for generating new phases to limit the growth of $\beta-\mathrm{Mg}_{17} \mathrm{Al}_{12}$ and modify its microstructure, and eventually improve the mechanical properties of $\mathrm{Mg}-\mathrm{Al}$ series alloys ${ }^{[4-7]}$. Simultaneously, T6 treatment that can also achieve similar goals has attracted more attention due to its low cost and convenience. This is done by making $\mathrm{Mg}_{17} \mathrm{Al}_{12}$ dissolved into $\alpha-\mathrm{Mg}$ matrix and then precipitated once again.

Semisolid metal (SSM) processing is recognized as

\section{*Hong Yan}

Male, born in 1962, Ph. D, Prof. Research interests: semi-solid processing of magnesium alloys and aluminum alloys.

E-mail: yanhong_wh@163.com an outstanding technique for $\mathrm{Mg}$ alloys. Its advantages are compared to the conventional die casting processes, including the potential of producing near-net shape and high-integrity components, low processing temperature that resolved the problem of oxidation, and effective burning in $\mathrm{Mg}$ alloys processing ${ }^{[8]}$.

Several works have studied the microstructure evolution of AZ91D alloy fabricated by SSM processing during heat treatment ${ }^{[9-10]}$, but few studies related to the SSM processed $\mathrm{Mg}$-Al series alloys containing $\mathrm{RE}$ have been reported. Also, it is well known that different casting processes will result in a variation of the microstructure, which could influence dissolution and precipitation kinetics of $\mathrm{Mg}_{17} \mathrm{Al}_{12}$ during subsequent heat treatment.

In this present study, solution treatment (ST) at $410{ }^{\circ} \mathrm{C}$ was used to process a rheo-forming AZ91-Y alloy. The aim was to detail the alloy's microstructure and hardness before and after ST, and to acquire the appropriate solution duration for subsequent aging treatment. The effect of RE (Y) on kinetics of $\mathrm{Mg}_{17} \mathrm{Al}_{12}$ dissolution and the effect of the rheo-forming technique on alloy composition homogenization were also analyzed. 


\section{Experimental procedure}

The samples for ST were cut from the component manufactured by the rheo-forming technology. The raw material consists of commercial AZ91 alloy and Mg-30wt.\%Y master alloy. The semi-solid slurry of AZ91-Y alloy was fabricated using ultrasonic vibration, with reference to our previous work ${ }^{[11]}$. The semi-solid slurry was transferred to the lower part of the mould preheated to approximately $580{ }^{\circ} \mathrm{C}$ (also the slurry transition temperature), and the upper part was maintained at $290{ }^{\circ} \mathrm{C}$. Finally, the component with $12 \mathrm{~mm}$ in thickness was achieved using the forming pressure of $100 \mathrm{MPa}$. The composition of the rheo-forming AZ91-Y alloy component was given as follows: $\mathrm{Al}$ 9.16, Zn 0.54, Y 2.10, other elements 0.32, Mg balance, wt.\%.

Subsequently, ST was performed to process the rheoforming AZ91-Y alloy. A resistance furnace with an accuracy of $\pm 1{ }^{\circ} \mathrm{C}$ was used with the protection of argon gas. In order to understand the details of microstructure evolution and acquire the appropriate solution duration, according to the $\mathrm{Mg}$-Al binary phase equilibrium diagram, the ST was carried out at $410{ }^{\circ} \mathrm{C}$ for durations ranging from $5 \mathrm{~min}$ to $36 \mathrm{~h}$. After that, the solutiontreated samples were quickly water quenched.

A Nikon ECLIPSE-MA200 optical microscope (OM), a Nova NanoSEM-450 scanning electron microscope (SEM) equipped with Inca 250X-MAX50 energy dispersive spectroscopy (EDS), and X-ray diffraction (XRD) using $\mathrm{CuK} \alpha$ radiation were used to observe and analyze the microstructure of the rheoforming AZ91-Y alloy before and after ST. The samples for $\mathrm{OM}$ and SEM inspections were mounted, ground, polished and then etched in an aqueous solution of $5 \mathrm{~g}$ oxalic acid (s), $1 \mathrm{ml}$ concentrated $\mathrm{HNO}_{3}$ (1), $50 \mathrm{ml} \mathrm{H} \mathrm{H}_{2} \mathrm{O}$ (1). The hardness changes during ST were determined by HV-1000 Vickers using a load of $0.3 \mathrm{kgf}$, and the duration of load was $15 \mathrm{~s}$. No fewer than 7 separate test results were averaged for each hardness value reported here.

\section{Results and discussion}

\subsection{As-cast microstructure}

Figure 1 shows the SEM images of the rheo-forming AZ91-Y alloy at (a) transition region and (b) secondary solidification region. It can be seen that the alloy's microstructure is not uniform, and according to the XRD analysis (Fig.2a), consists of $\alpha-\mathrm{Mg}$ and $\beta-\mathrm{Mg}_{17} \mathrm{Al}_{12}$ as well as $\mathrm{Al}_{2} \mathrm{Y}$ compound. The nearspherical particles are the primary $\alpha-\mathrm{Mg}$ in average grain size of roughly $100 \mu \mathrm{m}$, as seen at the left corner of Fig.1 (a). The fine dendrites as shown in both Fig.1 (a) and (b) are secondarily solidified $\alpha-\mathrm{Mg}$.

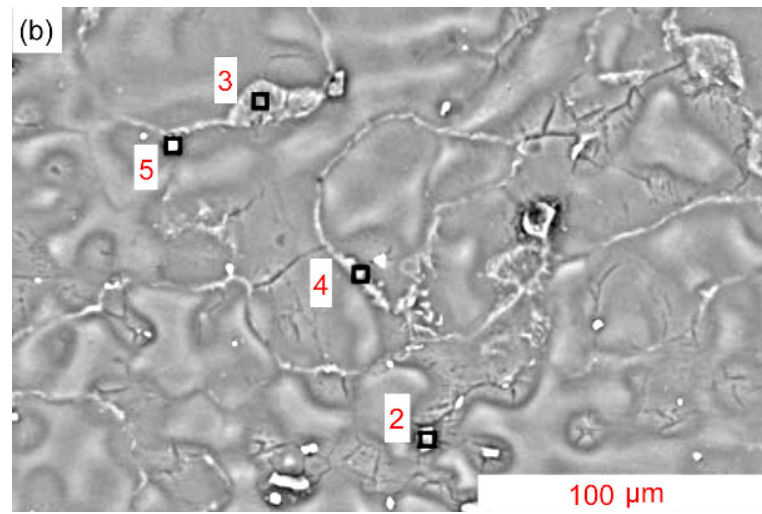

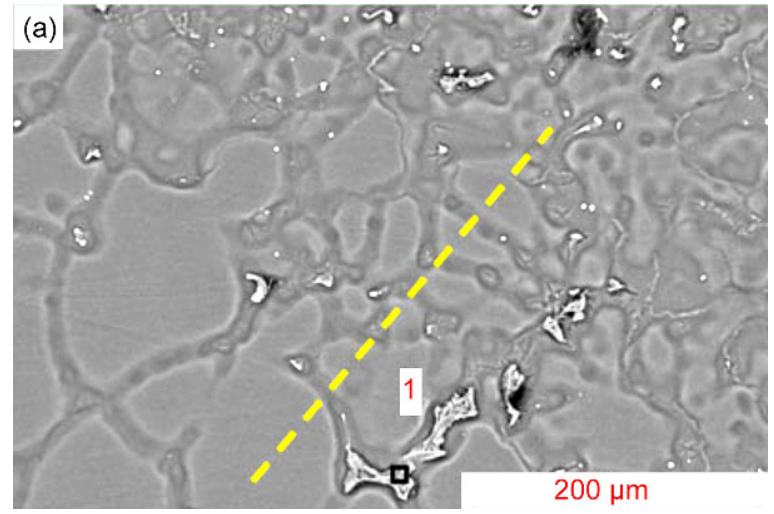

Fig. 1: SEM images of rheo-forming AZ91-Y alloy: (a) transition region and (b) secondary solidification region

The silvery particle with the maximum grain size of $8 \mu \mathrm{m}$ (position 5) according to Fig. 3 was seen as $\mathrm{Al}_{2} \mathrm{Y}$. The new compound was produced at liquidus by the impact of ultrasonic vibration ${ }^{[11]}$. Moreover, different contents of $\mathrm{Mg}$ and $\mathrm{Al}$ and different atom ratios of $\mathrm{Mg}$ and $\mathrm{Al}$ for other positions are also shown in Fig. 3. Combined with the detected $\mathrm{Mg}_{17} \mathrm{Al}_{12}$ peaks in Fig. 2(a), the irregular (position 1), blocky (position 2), lamellar (position 3) and fibrous (position 4) phases were preliminarily regarded as $\beta-\mathrm{Mg}_{17} \mathrm{Al}_{12}$.

Generally, different morphologies of $\beta$ phases are associated with their conditions of nucleation and growth. Alloys with $\mathrm{Al}$ contents less than about 10wt.\% exhibit eutectic morphologies that are referred to as partially or fully divorced ${ }^{[12-13]}$. A partially divorced eutectic morphology is characterized by 'islands' of eutectic $\alpha-\mathrm{Mg}$ (dark spots) within the $\beta-\mathrm{Mg}_{17} \mathrm{Al}_{12}$ phase, but the bulk of the $\alpha-\mathrm{Mg}$ is still outside the $\mathrm{Mg}_{17} \mathrm{Al}_{12}$ particle, as shown

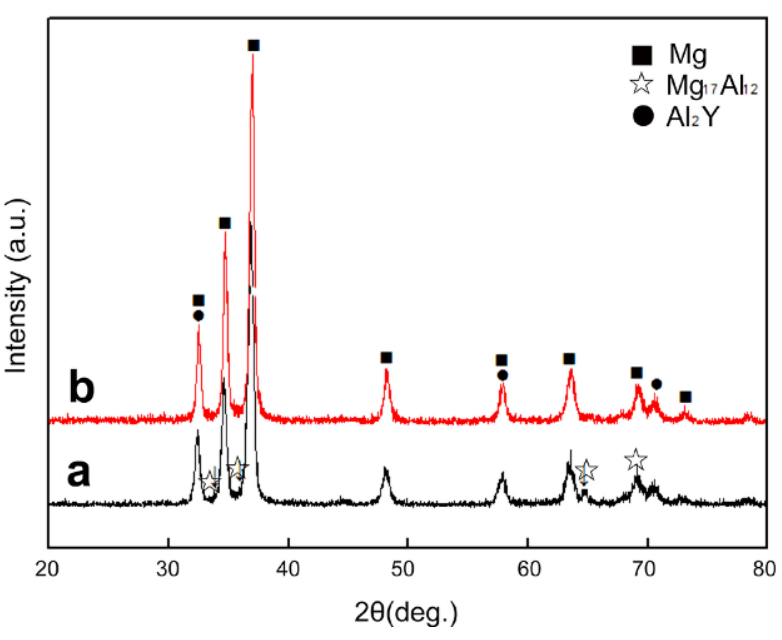

Fig. 2: XRD patterns of rheo-forming AZ91-Y alloy: (a) As-cast and (b) solution-treated at $410^{\circ} \mathrm{C}$ for $28 \mathrm{~h}$ 

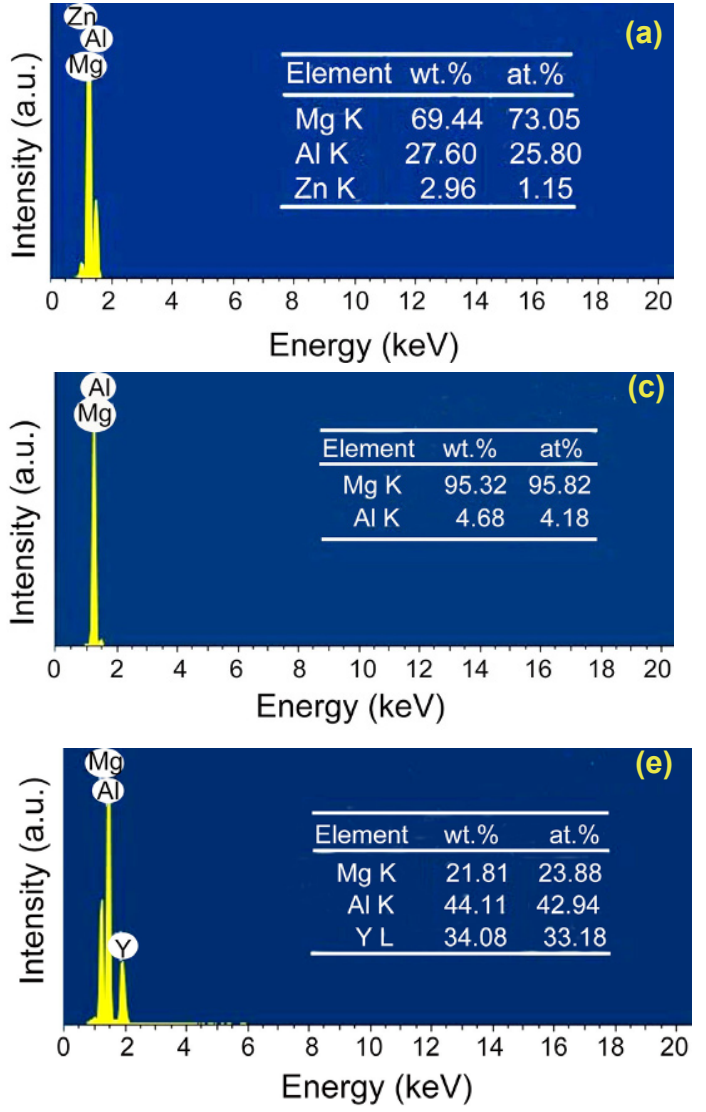

in Fig.1 (a) (position 1) ${ }^{[12]}$. In addition, there is a fully divorced morphology where the two eutectic phases are completely separated. Each interdendritic region consists of a single $\beta-\mathrm{Mg}_{17} \mathrm{Al}_{12}$ particle surrounded by 'eutectic' $\alpha-\mathrm{Mg}$, which has grown from the preferentially formed dendrites $\alpha-\mathrm{Mg}{ }^{[13]}$. As shown in Fig.1 (b) (position 2), however, the 'eutectic' $\alpha-\mathrm{Mg}$ cannot be easily discerned. It is notable that the blocky $\mathrm{Mg}_{17} \mathrm{Al}_{12}$ exhibits its smooth and compact appearance, corresponding to the fully divorced condition.

On the other hand, the effect of Al content on eutectic morphology should also be considered. The trend of eutectic morphologies affected by element composition has been described in detail by Nave et al ${ }^{[14-15]}$, that is, the eutectic tends to become less divorced with increasing $\mathrm{Al}$ content. According to the EDS results in Fig. 3 (a) and (b), the weight fraction of $\mathrm{Al}$ within the irregular and blocky eutectic is $27.6 \%$ and $23.36 \%$ respectively. So once again, the irregular $\beta-\mathrm{Mg}_{17} \mathrm{Al} 1_{12}$ was regarded as the partially divorced eutectic. And the blocky one was seen as the fully divorced eutectic. In addition, the element of zinc ( $\mathrm{Zn}$ ) was detected in these two types of eutectics, but its content has no obvious difference.

It is generally believed that the completion of eutectic solidification does not mean the end of phase transformation in a cast $\mathrm{Mg}-\mathrm{Al}$ alloy. When the cooling rate of the casting is sufficiently slow, precipitation may occur in the $\alpha-\mathrm{Mg}$ supersaturated areas ${ }^{[12]}$. In this case, the furnace temperature of $290{ }^{\circ} \mathrm{C}$ is just conducive to create a relatively low cooling rate. As shown in Fig. 3 (c) and (d), the $\mathrm{Al}$ contents in both of lamellar $(4.68 \%)$ and fibrous $(8.62 \%)$ precipitates are much lower than those in eutectics. This can be attributed to the
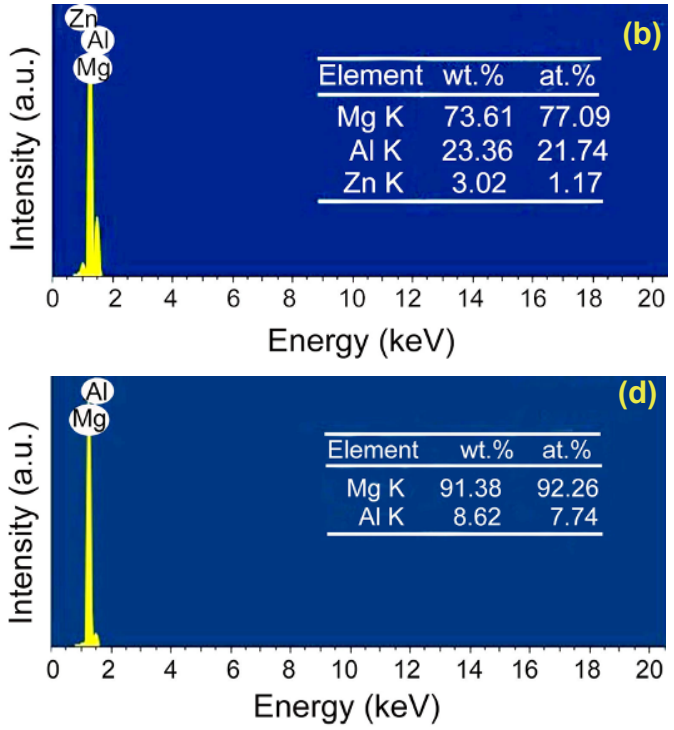

Fig. 3: EDS results of different locations marked in Fig.1: (a) location 1, (b) location 2, (c) location 3, (d) location 4 and (e) location 5

excessive $\mathrm{Mg}$ by the $\alpha-\mathrm{Mg}$ solid solution matrix. The lamellae structure (position 3) involves the lamellar growth of $\mathrm{Mg}_{17} \mathrm{Al}_{12}$ into the $\alpha-\mathrm{Mg}$ grains, corresponding to the discontinuous precipitation ${ }^{[12]}$. Zhu et al. ${ }^{[16]}$ also found the similar $\beta$-lamellae structure that mostly appeared to grow near the eutectic $\mathrm{Mg}_{17} \mathrm{Al}_{12}$. This is because these regions have relatively higher Al contents. For the fibrous phase located at position 4, its unbroken structure indicates the continuous precipitation to some degree.

Therefore, by considering the above factors (XRD diffraction peak, morphology and structure of phase as well as Al content), the irregular (position 1), blocky (position 2), lamellar (position 3 ) and fibrous (position 4) phases were all confirmed as $\beta-\mathrm{Mg}_{17} \mathrm{Al}_{12}$.

\subsection{Microstructure evolution}

According to the Mg-Al binary equilibrium phase diagram, ST causes the $\beta$ phase to dissolve into the $\alpha-\mathrm{Mg}$ matrix. Generally, the dissolution of $\beta$ phase is closely linked to the concentration gradient and diffusion kinetics of solute atoms (Al). As shown in Fig. 4, the distribution of $\mathrm{Mg}$, $\mathrm{Al}$ contents within $\alpha-\mathrm{Mg}$ matrix across the transition area (along the yellow line depicted in Fig.1 (a) was detected. It can be seen that the $\mathrm{Al}$ content increases notably from primary $\alpha-\mathrm{Mg}$ aggregates to secondarily solidified dendrites. This significant variation of Al content should be linked to solute partition. During the alloy solidification process, abundant $\mathrm{Al}$ atoms are always repelled to the front of the liquidsolid interface and enrich the residual liquid.

At this point, the involved details of solidification stages should be introduced. Firstly, $\mathrm{Al}_{2} \mathrm{Y}$ compound was generated 

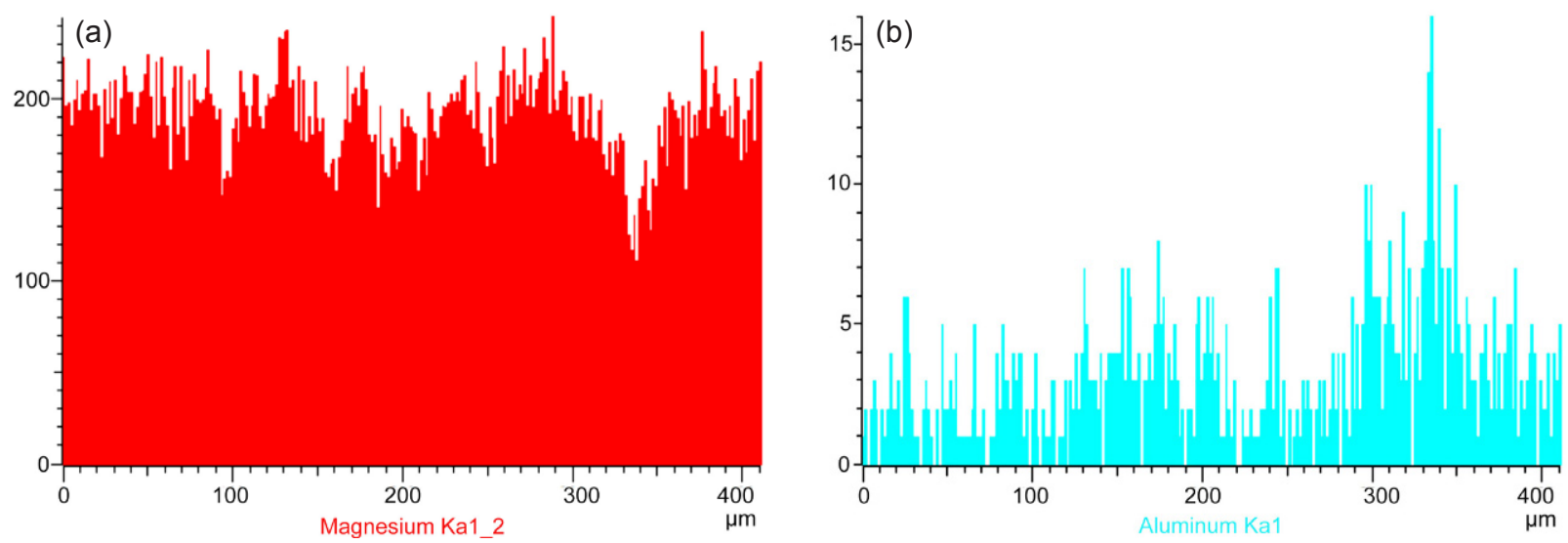

Fig. 4: Line scanning analysis maps across transition area for (a) Mg and (b) Al elements

using ultrasonic vibration. As the temperature of the melt was decreased, the primary $\alpha-\mathrm{Mg}$ grains began to nucleate and grow. In addition, due to the dispersive impact of ultrasonic vibration, the near-spherical $\alpha-\mathrm{Mg}$ should be evenly distributed during the semisolid slurry fabrication process ${ }^{[11]}$. However, in this case, the primary $\alpha-\mathrm{Mg}$ exhibits a state of aggregation, which contributes to the subsequent series of processes without ultrasonic vibration. In the forming stage, one segment of $\alpha-\mathrm{Mg}$ grains grew, attaching to the primary ones, and the other segments were dependent on spontaneous nucleation. Again, as the alloy temperature continued to decrease, by virtue of the $\mathrm{Al}$ partition and relatively low cooling rate, eutectic reaction and the following precipitation were performed.

As shown in Fig. 5(a)-(f), detailed observations by OM revealed the microstructure evolution of alloy after ST for durations ranging from $5 \mathrm{~min}$ to $36 \mathrm{~h}$. At the early stage, in the first $5 \mathrm{~min}$ [Fig. 5(a)], $\beta$ particles existing within both of the primary $\alpha-\mathrm{Mg}$ aggregates and secondarily solidified region have been nearly dissolved. However, previous studies ${ }^{[9-10]}$ reported that the complete dissolution time needed for $\beta-\mathrm{Mg}_{17} \mathrm{Al}_{12}$ of a semi-solid processed AZ91 alloy is approximately $3 \mathrm{~h}$. In this case, the main reason is that the addition of $2.10 \mathrm{wt} . \% \mathrm{Y}$ can induce the production of $\mathrm{Al}_{2} \mathrm{Y}$ compound, reducing the $\mathrm{Al}$ content for producing $\beta-\mathrm{Mg}_{17} \mathrm{Al}_{12}{ }^{[17-18]}$. Combined with the weak $\mathrm{Mg}_{17} \mathrm{Al}_{12}$ diffraction peaks in Fig. 2(a), the $\beta$ phase can be dissolved in such a short time. At the same time, it should be noted that the sharp grain boundaries emerged in the secondarily solidified region.

It is generally believed that the $\beta$ phase tends to be dissolved into the surrounding $\alpha-\mathrm{Mg}$, indicating the alloy needs a sufficient time to become a homogenized composition. As the ST duration increases to $1 \mathrm{~h}$ [Fig.5(b)-(c)], there are two characteristics. One is the gradual disappearance of secondarily solidified $\alpha-\mathrm{Mg}$ dendrites. The other is the obscurity of primary $\alpha-\mathrm{Mg}$ boundaries. These two are linked to the diffusion of solute atoms (Al).

When the ST duration is prolonged to $6 \mathrm{~h}$ [Fig.5(d)], it is clearly seen that the border between primary $\alpha-\mathrm{Mg}$ aggravates and the secondarily solidified region has already been unclear.
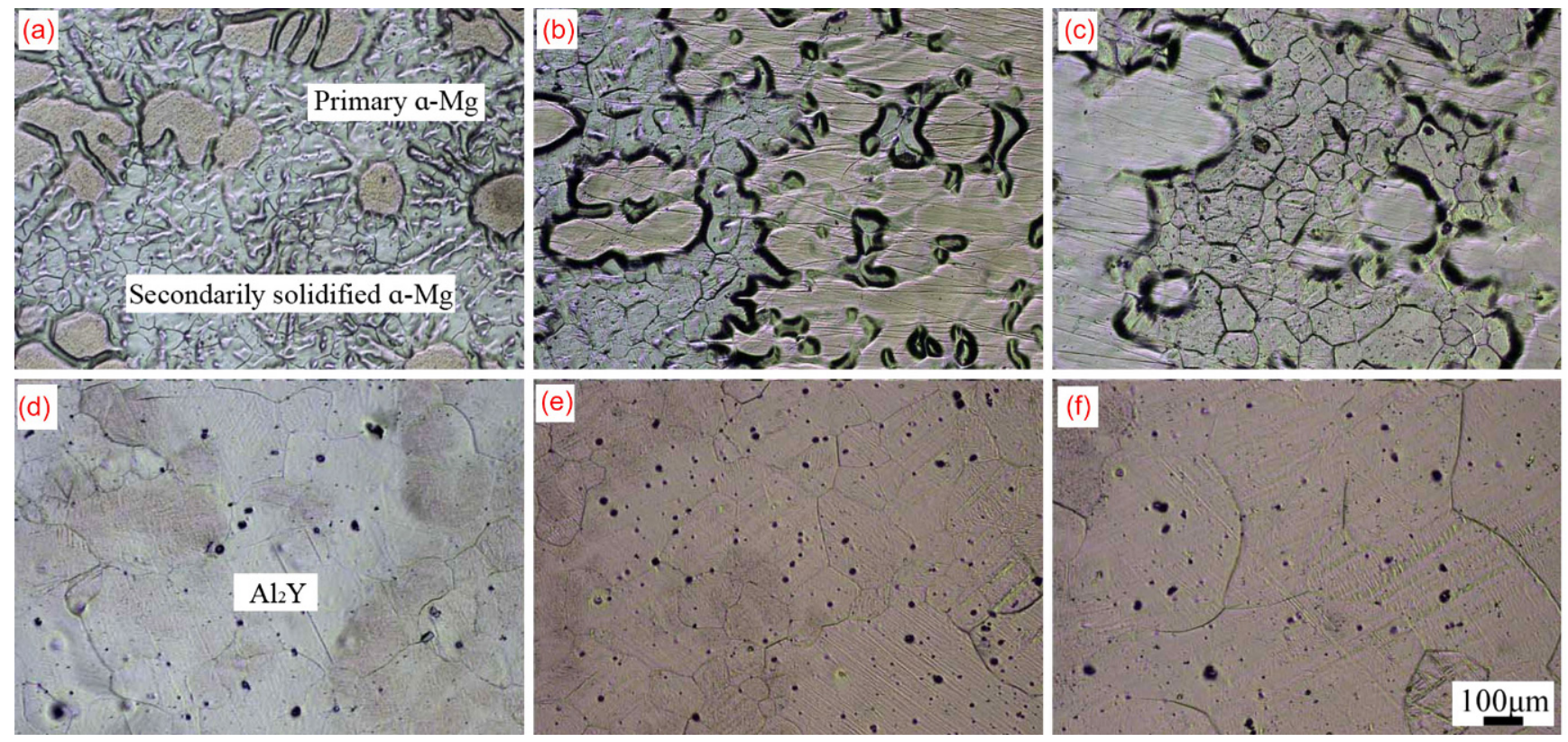

Fig. 5: OM microstructures of rheo-forming AZ91-Y alloy solution-treated at $410^{\circ} \mathrm{C}$ for (a) $5 \mathrm{~min}$, (b) $30 \mathrm{~min}$, (c) $1 \mathrm{~h}$, (d) $6 \mathrm{~h}$, (e) $28 \mathrm{~h}$ and (f) $36 \mathrm{~h}$ 
In addition, a great many black particles are displayed in this microstructure, which are regarded as $\mathrm{Al}_{2} \mathrm{Y}$ based on their grain size and morphology. When the ST duration reaches $28 \mathrm{~h}$, the outline of primary $\alpha-\mathrm{Mg}$ has faded away completely, and the microstructure shows flat. In other words, it means that the element composition (Al) has nearly been homogenized. As shown in Fig. 2(b), XRD analysis of the rheo-forming AZ91-Y alloy processed by ST for $28 \mathrm{~h}$ revealed that there was no sign of $\mathrm{Mg}_{17} \mathrm{Al}_{12}$. According to the above discussions, it means the supersaturated $\alpha-\mathrm{Mg}$ solid solution has already formed. Aging the rheo-forming AZ91-Y alloy is suitable at this time.

The order of the disappearance for primary $\alpha-\mathrm{Mg}$ and secondarily solidified $\alpha-\mathrm{Mg}$ can be explained via thermodynamic analysis. In fact, atoms on the surface of a particle are thermodynamically less stable than the ones in the interior. In views of the crystal structure, all the atoms inside are bonded to more neighbors and are quite stable, but atoms on the surface are bonded to fewer neighbors, which makes these surface atoms less stable. In other words, the difficulty of $\mathrm{Al}$ diffusion is dependent on the grain size of $\alpha-\mathrm{Mg}$. Hence, that the finer $\alpha-\mathrm{Mg}$ dendrites disappeared before the larger primary $\alpha-\mathrm{Mg}$ aggregates has been made clear.

Besides, $\mathrm{Al}_{2} \mathrm{Y}$ still retained its size and morphology during ST. It is generally performed as the thermal stable phase, because of its high melting point and low thermal expansion coefficient ${ }^{[19]}$.

As exhibited in Fig. 6(a), SEM image of the solutiontreated $(28 \mathrm{~h})$ alloy was inspected to determine the phase morphologies. The silvery particle indicated by the red arrow is $\mathrm{Al}_{2} \mathrm{Y}$ compound, since the $\mathrm{Al} / \mathrm{Y}$ ratio (68.03/28.18) is close to the nominal one, as shown in Fig. 6(b). Moreover, it can hardly be distinguished where the primary $\alpha-\mathrm{Mg}$ is compared to the
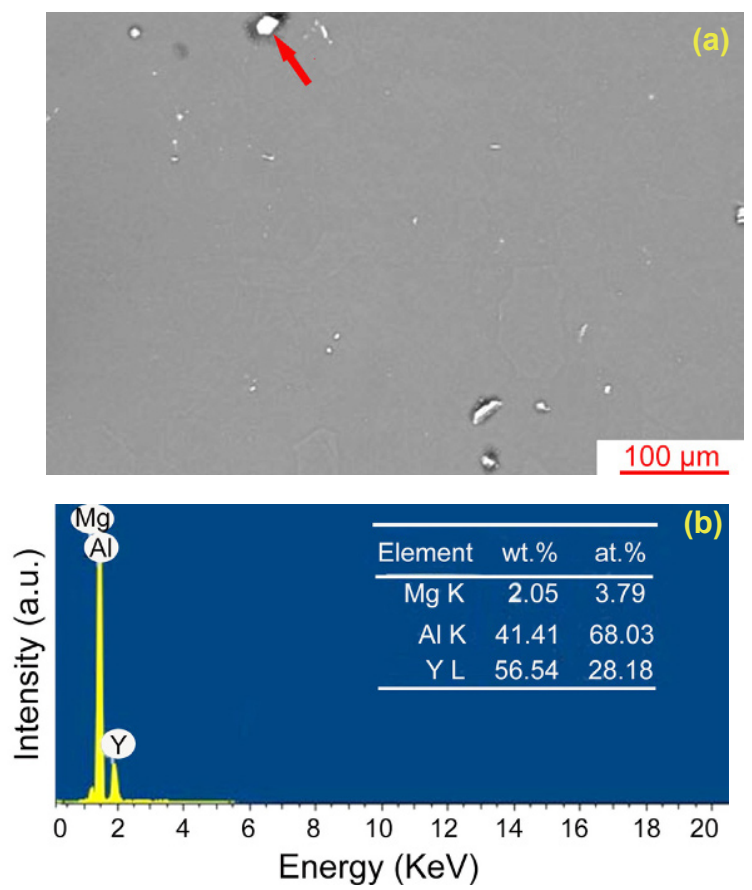

Fig. 6: (a) SEM image of rheo-forming AZ91-Y alloy after solution-treatment for $28 \mathrm{~h}$, (b) EDS result of the silvery particle (in Fig. 6a) pointed by red arrow secondarily solidified $\alpha-\mathrm{Mg}$. The grey matrix exhibits a much smoother surface when compared to the as-cast microstructure as shown in Fig. 1(a) and (b).

In order to acquire the appropriate solution duration, further treatment (at $410{ }^{\circ} \mathrm{C}$ for beyond $28 \mathrm{~h}$ ) was done. Observation indicated that the $\alpha-\mathrm{Mg}$ grains grew up sharply after being treated for $36 \mathrm{~h}$ [Fig.5 (f)]. The traditional grain shape was converted to the irregular morphology due to the mergence and growth of grains. During ST, grain growth is determined generally that the finer grains could easily have been swallowed by the larger ones ${ }^{[20]}$. Therefore, the appropriate ST duration for the rheo-forming AZ91-Y alloy at $410{ }^{\circ} \mathrm{C}$ is approximately $28 \mathrm{~h}$.

The microstructure evolution of the alloy during ST can be concluded in three processes: (a) the dissolution of nonequilibrium $\beta$ phase into $\alpha-\mathrm{Mg}$ matrix, (b) the gradual disappearance of both the primary and the secondarily solidified $\alpha-\mathrm{Mg}$, (c) drastic grain growth.

In this case, the rheo-forming AZ91-Y alloy spent nearly $28 \mathrm{~h}$ on composition homogenization. However, other researchers ${ }^{[9-10]}$ reported that the ST duration at $410{ }^{\circ} \mathrm{C}$ required for semisolid processed AZ91 alloy (containing more $\mathrm{Mg}_{17} \mathrm{Al}_{12}$ ) was much shorter. This contributes to the inhomogeneous distribution of both of the primary $\alpha-\mathrm{Mg}$ and secondarily solidified $\alpha-\mathrm{Mg}$ within the rheo-forming AZ91-Y alloy, and leads to a relatively long time for the solute atoms $(\mathrm{Al})$ diffusing from secondary solidification region to primary $\alpha-\mathrm{Mg}$ aggregates. Wang et al ${ }^{[9]}$ reported Al atoms would diffuse from the super-saturated secondary $\alpha-\mathrm{Mg}$ solid solution to the primary $\alpha-\mathrm{Mg}$, so that Al-rich halos were obviously noted. It can be concluded that the better the $\alpha-\mathrm{Mg}$ distribution, the shorter ST duration for composition homogenization alloy was needed.

\subsection{Hardness change response to solution treatment}

Figure 7 shows the variation of alloy Vickers-hardness against ST duration at $410{ }^{\circ} \mathrm{C}$. The alloy hardness in the as-cast state is about $67.71 \mathrm{HV}$. After ST, firstly, the hardness shows a sharp reduction, relating to the rapid dissolution of strengthening phase of $\beta$. In fact, a large amount of $\mathrm{Al}$ atoms dissolved into $\alpha-\mathrm{Mg}$

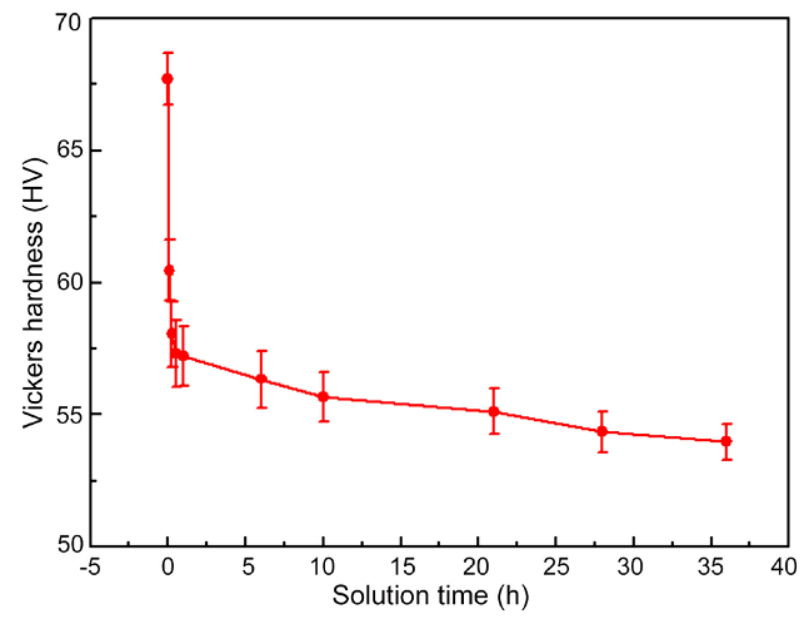

Fig. 7: Vickers hardness versus ST duration for rheoforming AZ91-Y alloy 
can induce an increment in strength by solution strengthening ${ }^{[21]}$, but it nearly does not work under this condition of $\beta$-phase disappearance. In other words, the disappearance of $\beta$-phase plays a more important role in the variation of alloy hardness. As the ST duration is increased, the hardness gradually reaches a minimum level. This means that the alloy hardness can barely be affected by the composition homogenization and mergence of grains. In conclusion, according to the microstructure evolution and hardness change, the alloy appropriate ST duration is approximately $28 \mathrm{~h}$.

\section{Conclusion}

Solution treatment (ST) at $410{ }^{\circ} \mathrm{C}$ was applied to a rheoforming AZ91-Y alloy with ST durations ranging from $5 \mathrm{~min}$ to $36 \mathrm{~h}$. The as-cast microstructure of rheo-forming AZ91-Y alloy consisted of $\alpha-\mathrm{Mg}, \beta-\mathrm{Mg}_{17} \mathrm{Al}_{12}$ and $\mathrm{Al}_{2} \mathrm{Y}$. After ST for 5 min, the $\beta-\mathrm{Mg}_{17} \mathrm{Al}_{12}$ phase of alloy was nearly dissolved. With the increasing of ST duration to $28 \mathrm{~h}$, both the primary and secondarily solidified $\alpha-\mathrm{Mg}$ grains faded away. At the same time, the alloy exhibited a much smoother surface due to the diffusion of solute atoms (Al). During ST, the thermal stable phase of $\mathrm{Al}_{2} \mathrm{Y}$ produced by ultrasonic vibration retained its size and morphology. As the ST duration increased, the alloy hardness decreased sharply at first, and then gradually reached a minimum level. The alloy's appropriate ST duration at $410^{\circ} \mathrm{C}$ was approximately $28 \mathrm{~h}$.

\section{References}

[1] Ali Y, Qiu D, Jiang B, et al. Current research progress in grain refinement of cast magnesium alloys: A review article. Journal of Alloys and Compounds, 2015, 619: 639-651.

[2] Zhang Q Q, Cao Z Y, Liu Y B, et al. Study on the microstructure evolution and rheological parameter of semisolid Mg-10Al-4Zn alloys. Materials Science and Engineering A, 2008, 478(1-2): 195-200.

[3] Peng L, Chen G, Zhao Y T, et al. Influence of solution treatment on microstructure and properties of in-situ $\mathrm{Mg}_{2} \mathrm{Si} /$ AZ91D composites. Transactions of Nonferrous Metals Society of China, 2011, 21(11): 2365-2371.

[4] Nami B, Shabestari SG, Razavi H, et al. Effect of Ca, RE elements and semi-solid processing on the microstructure and creep properties of AZ91 alloy. Materials Science and Engineering A, 2011, 528(3): 1261-1267.

[5] Zhang X, Deng K K, Li W J, et al. Microstructure and mechanical properties of Mg-Al-Ca alloy influenced by $\mathrm{SiC}_{\mathrm{p}}$ size. Materials Science and Engineering A, 2015, 647: 15-27.

[6] Yang M B, Pan F S, Cheng R J, et al. Effect of semi-solid isothermal heat treatment on the microstructure of Mg-6Al$1 \mathrm{Zn}-0.7 \mathrm{Si}$ alloy. Journal of Materials Processing Technology, 2008, 206(1-3): 374-381.

[7] Kaveh M A, Alireza T, Farzad K. The effect of different content of $\mathrm{Al}, \mathrm{RE}$ and $\mathrm{Si}$ element on the microstructure, mechanical and creep properties of $\mathrm{Mg}-\mathrm{Al}$ alloys. Materials Science and Engineering A, 2009, 523(1-2): 1-6.

[8] Du X H, Zhang E L. Microstructure and mechanical behavior of semi-solid die-casting AZ91D magnesium alloy. Materials Letters, 2007, 61(11-12): 2333-2337.

[9] Wang Y, Liu G J, Fan Z Y. Microstructural evolution of rheodiecast AZ91D magnesium alloy during heat treatment. Acta Materialia, 2006, 54(3): 689-699.

[10] Yang L J, Wei Y H, Hou L F. Microstructure evolution of thixomolding AZ91D magnesium alloy during heat treatment. Journal of Materials Science, 2010, 45(13): 3626-3634.

[11] Huang W X, Yan H. Preparation and theoretic study of semi-solid $\mathrm{Al}_{2}$ Y/AZ91 magnesium matrix composites slurry by ultrasonic vibration. Journal of Rare Earths, 2014, 32(6): 573-578.

[12] Dahle A K, Lee Y C, Nave M D, et al. Development of the ascast microstructure in magnesium-aluminium alloys. Journal of Light Metals, 2001, 1(1): 61-72.

[13] Yakubtsov I A, Diak B J, Sager C A, et al. Effects of heat treatment on microstructure and tensile deformation of $\mathrm{Mg}$ AZ80 alloy at room temperature. Materials Science and Engineering A, 2008, 496(1-2): 247-255.

[14] Nave M D, Dahle A K, Stjohn D H. Magnesium technology 2000. Warrendale: The Minerals, Metals and Materials Society, 2000: 233-242.

[15] Nave M D, Dahle A K, Stjohn D H. Magnesium technology 2000. Warrendale: The Minerals, Metals and Materials Society, 2000: 243-250.

[16] Zhu T P, Chen Z W, Gao W. Dissolution of eutectic $\beta-M g_{17} A l_{12}$ phase in magnesium AZ91 cast alloy at temperatures close to eutectic temperature. Journal of Materials Engineering and Performance, 2010, 19(6): 860-867.

[17] Kashefi N, Mahmudi R. The microstructure and impression creep behavior of cast AZ80 magnesium alloy with yttrium additions. Materials and Design, 2012, 39: 200-210.

[18] Qi Q J, Liu Y B, Yang X H. Friction and wear characteristics of rare earth containing Mg-Al alloy. Journal of Rare Earths, 2003, 21(2): 157-162.

[19] Wang S J, Wu G Q, Li R H, et al. Microstructures and mechanical properties of $5 \mathrm{wt} . \% \mathrm{Al}_{2} \mathrm{Yp} / \mathrm{Mg}$-Li composite. Materials Letters, 2006, 60(15): 1863-1865.

[20] Huang H J, Chen T J, Ma Y, et al. Microstructural evolution during solution treatment of thixoformed AM60B Mg alloy. Transactions of Nonferrous Metals Society of China, 2011, 21(4): 745-753.

[21] Cáceres C H, Poole W J, Bowles A L, et al. Section thickness, macrohardness and yield strength in high-pressure diecast magnesium alloy AZ91. Materials Science and Engineering A, 2005, 402(1): 269-277.

The work was financially supported by the National Science Foundation of China (51165032), Ministry of Education Special Research Fund of the Doctoral Program for Higher Education (20133601110001), Innovative Group of Science and Technology of College of Jiangxi Province (00008713), and the Production, Teaching and Research Cooperation Plan of Nanchang Non-party Experts and Doctors (2012-CYH-DW-XCL-002). 